\title{
NORMAS EDITORIALES
}

\author{
TLALOCAN \\ Revista de fuentes para el conocimiento \\ de las culturas indígenas de México
}

Tlalocan publica fuentes relacionadas con las culturas indígenas de México y Mesoamérica, tanto documentales como recopiladas de textos orales. También se aceptan textos en lenguas indígenas emparentadas con lenguas mexicanas, sean de origen documental u oral. Se busca que los textos tengan interés etnográfico o histórico además del interés lingüístico. Asimismo se incluyen notas y reseñas de libros.

\section{LINEAMIENTOS GENERALES}

1. Tlalocan sólo recibe trabajos inéditos.

2. Se publican colaboraciones en español y en inglés.

3. Todo trabajo entregado para ser publicado en Tlalocan se somete a dictaminación.

\section{LAS COLABORACIONES}

TEXTOS DOCUMENTALES. Los textos documentales que no hayan sido publicados anteriormente o cuya edición sea de difícil acceso. De preferencia debe presentarse un estudio introductorio sobre el contexto histórico, la identificación y la ubicación actual del documento. Además del texto pueden incluirse imágenes del documento original.

TEXTOS EN LENGUA INDíGena. La presentación de los textos varía según las preferencias de cada autor y el público al que vaya dirigido; las recomendaciones para distintos tipos de formatos se detallan abajo. También debe incluirse un estudio introductorio con información pertinente, la cual deberá contener una explicación del origen del texto, las características de los narradores, el modo y las circunstancias de su recopilación (dado el caso), y las convenciones que se utilizan, sean de índole filológica o relativas al sistema ortográfico y de glosado. Si se incluye un análisis filológico, etnográfico, narratológico, o gramatical, éste deberá ser sucinto y estar limitado a algún aspecto sobresaliente del texto. No se aceptan artículos con investigaciones gramaticales amplias y que no sean relevantes para el texto presentado. 
NOTAS Y RESEÑAS. Notas breves y reseñas de libros y artículos recientes que sean relevantes para la filología, la descripción y la documentación de lenguas indígenas de México. Se sugiere que las reseñas tengan descripción, análisis y conclusión en torno a la obra reseñada.

\section{PRESENTACIÓN DE ORIGINALES}

1. Los trabajos deben presentarse en formato electrónico en un documento para Word, el archivo correspondiente puede entregarse en $\mathrm{CD}$, o ser enviado por correo electrónico. De manera opcional puede agregarse una versión en PDF.

2. Deben presentarse también los originales impresos en páginas numeradas.

3. Las colaboraciones deben estar lo más acabado posible en términos gramaticales y técnicos. Si alguna colaboración presenta graves problemas en este sentido será devuelta al autor para su revisión.

4. El título del artículo debe aparecer en español e inglés.

5. Incluir dos resúmenes del artículo: uno en español y otro en inglés, no mayores a 200 caracteres cada uno.

6. Anotar cinco palabras clave, tanto en español como en inglés.

7. Los colaboradores deberán especificar el nombre completo de la institución a la que están adscritos y su correo electrónico. Esta información debe incluirse al final del trabajo enviado, o en un archivo adjunto.

8. La traducción de un término en lengua indígena debe aparecer entre comillas simples (' '). Una cita textual, o transcripción de un ejemplo de habla, o de un texto, deben indicarse con comillas dobles (" ”). Un elemento léxico, o una frase, deben ir en cursivas.

9. Elaborar una lista de abreviaturas con las convenciones utilizadas en los análisis lingüísticos. Esta lista debe aparecer justo antes de las Referencias bibliográficas.

10. Si el autor introduce notas, deberán ir al pie de página.

11. Las referencias bibliográficas dentro del texto deben aparecer en forma abreviada, es decir, entre paréntesis, donde se consignan el apellido (su nombre sólo en caso de que su apellido coincida con el de otro autor citado), el año de edición y las páginas, después de dos puntos. Ejemplo: (Barlow, 1945: 74-75).

12. Deben seguirse los estilos especificados en el documento Plantilla de Estilo Tlalocan, disponible en la página web de Tlalocan (http://www.iifilologicas.unam.mx/tlalocan/).

a) Se aceptan únicamente los estilos que aparecen en dicho documento. Si un autor necesita un formato adicional o modificar uno existente, por favor contactar a los editores.

b) Se solicita a los autores no utilizar ningún estilo de párrafo distinto a los especificados en la Plantilla de Estilo. Asimismo, no debe usarse ningún macro.

c) Para dudas sobre el uso de estilos, por favor consultar el documento Uso de estilos en Word, también disponible en la página web, o contactar a los editores. 


\section{PRESENTACIÓN DE TEXTOS EN FORMATO CORRIDO}

1. En el caso de los textos en formato corrido, el autor debe especificar el formato que quiere para el texto, por ejemplo, ya sea en espejo (texto y traducción compaginados), ya sea el texto completo en lengua indígena y enseguida su traducción, u otros.

2. Los textos deben tener un sistema de numeración para identificar las correspondencias entre las versiones.

\section{PRESENTACIÓN DE EJEMPLOS Y TEXTO EN FORMATO INTERLINEAL}

1. Para presentar el análisis morfológico es indispensable tener el conocimiento necesario de la lengua para hacerlo. Si un autor se siente inseguro al respecto, se recomienda consultar al editor del número o entregar el texto en un formato corrido.

2. De preferencia, los ejemplos en el estudio introductorio deben tener corte morfológico y glosa, además de traducción libre.

3. Se recomienda presentar los textos en cuatro líneas:

$1^{a}$ línea: texto indígena

$2^{a}$ línea: cortes morfémicos

$3^{\text {a línea: glosa }}$

$4^{\mathrm{a}}$ línea: traducción libre

4. Puede ir una línea adicional para el texto en transcripción fonética o fonológica.

5. Puede ir una línea adicional para la traducción libre en inglés, además de español.

6. Las palabras en la línea que presenta los cortes morfémicos deben estar alineadas a la izquierda con las palabras en la línea de las glosas. Es indispensable que esto se haga mediante tabuladores. Se devolverá al autor todo artículo cuyos ejemplos sean alineados por medio de espacios.

7. Puede utilizarse cualquier técnica de glosado aunque se recomienda el uso de las Reglas de Glosado de Leipzig (http://www.eva.mpg.de/lingua/resources/glossing-rules.php). En cualquier caso, deberá incluirse una lista con las abreviaturas empleadas en las glosas (ésta se colocará justo antes de las Referencias bibliográficas).

\section{IMÁGENES}

1. Entregar imágenes en archivo independiente, en formato .TIFF, con resolución mínima de 300 puntos por pulgada y en millones de colores.

2. Indicar la ubicación de las imágenes dentro del texto, las cuales deberán incluir el pie de ilustración y los créditos.

3. Debe haber un archivo por cada imagen, con el nombre "imagen X" y con el número correspondiente. 


\section{REFERENCIAS BIBLIOGRÁFICAS}

Incorporar las referencias bibliográficas al final del texto, por orden alfabético y por año de publicación, con formato de párrafo francés, según los siguientes modelos:

\section{LIBROS}

APELLIDO, Nombre

Año Título. Número de edición (si no es la primera), volumen. Lugar: Editorial (Colección).

ACUÑA, René

1998 Temas del Popol Vuh. México: UnAM, Instituto de Investigaciones Filológicas (Ediciones Especiales, núm. 10).

CoE, Michael D.

1984 The Maya. $3^{\text {a }}$. edición. New York: Thames and Hudson.

FuRBEE, Louanna

1976 The Correct Language: A Grammar with Ethnographic Notes. New York: Garland Publishing.

LENKERSDORF, Carlos

1979 B'omak'umal tojol ab'al-kastiya. Diccionario tojolabal-español, vol. 1. Mexico: Editorial Nuestro Tiempo.

1981 B'omak'umal kastiya-tojol ab'al. Diccionario español-tojolabal, vol. 2. México: Editorial Nuestro Tiempo.

GARCÍA ICAZBALCETA, Joaquín

1954 Bibliografía mexicana del siglo XV. 2a . edición. México: FCE (Biblioteca Americana).

Notas:

- La entrada se hará por título cuando se trate de textos anónimos.

- Los títulos deben aparecer completos.

- $\quad$ No se traducirán los nombres de autores, editores, ciudades, editoriales y colecciones.

\section{ARTÍCULO EN REVISTA}

APELLIDO, Nombre

Año "Título del artículo", Título de Revista vol. (núm): páginas. Otra información (lugar de edición, etc.).

BARLOW, R. H., y George T. SMISOR

1943 "Introducing Tlalocan", Tlalocan I: 1.1. Sacramento: La Casa de Tlaloc. 
BRODY, Jill

1986 "Repetition as a rhetorical and conversational device in Tojolabal (Maya)", International Journal of American Linguistics 52(3): 255-274.

Zavala MaLdONADO, Roberto

1994 "Inverse alignment in Huastec", Función 15-16: 27-81.

Nota: para indicar las páginas de los artículos en revistas se usa dos puntos: 27-81.

\section{CAPÍTULO EN VOLUMEN}

APELLIDO, Nombre

Año "Título de capítulo", en Título, Nombre(s) de editor(es), editor, páginas, número de edición (si no es la primera), volumen. Lugar: Editorial (Colección).

Craig, Colette G.

1977 "Jacaltec: fieldwork in Guatemala", en Languages and their Speakers, Timothy Shopen, editor, pp. 2-57. Cambridge, Mass.: Winthrop.

BRown, Penelope, y Stephen C. LEvinson

1989 "Universals in language usage: politeness phenomena", en Questions and Politeness, Esther C. Goody, editora, pp. 56-289. Cambridge: Cambridge University Press.

BRODY, Jill

1990 "El realce en tojolab'al”, en Lecturas sobre la lingüística maya, Nora C. England y Stephen R. Elliott, compiladores, pp. 461-472. Antigua: Centro de Investigaciones Regionales de Mesoamérica.

Nota: para indicar las páginas de los capítulos en volumen se usa pp. 461-472.

\section{TESIS}

APELLIDO, Nombre

Año "Título de tesis". Tesis doctoral/de licenciatura, etc., Institución, Lugar (otra información).

BRODY, Jill

1982 "Discourse processes of highlighting in Tojolabal Maya morphosyntax". Tesis doctoral, Washington University, St. Louis, Missouri.

EDMONSON, Barbara

1988 "A descriptive grammar of Huastec (Potosino dialect)". Tesis doctoral, Tulane University, New Orleans, Louisiana. University Microfilms No. 8817287. 


\section{PONENCIA}

APELLIDO, Nombre

Año "Título de ponencia". Ponencia presentada en Nombre de Congreso, Lugar, día, mes (opcional).

BRODY, Jill

1985 "The grammar of particles in Tojolabal". Ponencia presentada en el Congreso Annual de la American Anthropological Association, Washington, D.C.

\section{OBRA TRADUCIDA}

APELLIDO, Nombre

Año Título, traducción, número de edición (si no es la primera), volumen. Lugar: Editorial (Colección).

COLLIER, George, y Elizabeth LOWERY QUARATIELLO

1994. Basta! Land and the Zapatista Rebellion in Chiapas. Oakland: Food First Books, traducción de Frank Bardacke, Leslie López y The Watsonville, California Human Rights Committee.

\section{AUTOR CON VARIOS TÍTULOS}

BERNAL, Ignacio

1962 Bibliografía de arqueología y etnografía. Mesoamérica y norte de México, 1514-1960. México: INAH.

1979 Historia de la arqueología mexicana. México: Porrúa.

MÁS DE UN AUTOR

APELLIDO, Nombre, Nombre APELLIDO y Nombre APELLIDO

DunCAN, S., y D. FisKE

1977 Face-to-Face Interaction: Research, Methods, and Theory. Hillsdale, New Jersey: Lawrence Erlbaum Associates.

FurBeE, Louanna, y Robert A. BENFER

1983 "Cognitive and geographic maps: Study of individual variation among Tojolabal Mayans", American Anthropologist 85: 305-334. 